\title{
In Situ Observation on the Mass Aggregation of Edible Sea Urchin Stomopneustes variolaris in Shingle Island, Gulf of Mannar
}

\section{Sadhukhan Koushik ${ }^{1}$ \\ Ch. Ramesh ${ }^{2}$ \\ T. Shunmugaraj ${ }^{3}$ (D) \\ M.V. Ramana Murthy ${ }^{4}$}

${ }^{1,2, s}$ National Centre for Coastal Research (NCCR), Ministry of Earth Sciences (MoES), NCCR Field Office, Mandapam camp, Ramnathapuram District, Tamil Nadu, India.

Email:Sadhukhan.1985@gmail.com Tel:91-9025251632

EEmail: chrameshpu@gmail.com Tel: $91-9474227148$

Email:raj@nccr.gov.in Tel:91-8056081193

${ }^{\text {}}$ National Centre for Coastal Research (NCCR), Ministry of Earth Sciences (MoES), Pallikaranai, Chennai, Tamil Nadu, India.

Email:_mor@ncor.gov.in Tel:91-(044)66783586

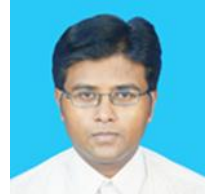

( Corresponding Author)

\section{Abstract}

This study report significant observation on the mass aggregation of sea urchin species Stomopneustes variolaris from Shingle Island. S. variolaris is well known edible sea urchin species to coastal population. Intensive underwater surveys were conducted during the period of January and February, 2019 at different sites of Mandapam group of Islands in Gulf of Mannar. $S$ .variolaris were found underneath and periphery of the dead reef, on the algal bed and on the exposed substratum. The density of the species 6-9 individuals / $\mathrm{m}^{2}$ was observed during the survey. Adult and young $S$. variolaris were recorded during the survey but juvenile was not observed as they usually hide within the dead rocks. The mass aggregation appears to be due to seasonal occurrence that exploit intensive grazing on macroalgae during the post monsoon in Gulf of Mannar. This study also discussed the commercial importance of this edible sea urchin species which could be an important food sources for the coastal population of Gulf of Mannar.

Keywords: Sea urchin, Stomopneusts variolaris, Aggregation, Behavior, Shingle Island, Gulf of Mannar.

Citation | Sadhukhan Koushik; Ch. Ramesh; T. Shunmugaraj; M.V. Ramana Murthy (2019). In Situ Observation on the Mass Aggregation of Edible Sea Urchin Stomopneustes variolaris in Shingle Island, Gulf of Mannar. Journal of Life Sciences Research, 6(1): $5-8$.

History:

Received: 17 December 2018

Received: 17 December 2018

Revised: 24 January 2019

Accepted: 27 March 2019

Published: 4 May 2019

Licensed: This work is licensed under a Creative Commons Attribution 3.0 License $(\mathrm{coc})$ )

Publisher: Asian Online Journal Publishing Group
Contribution/Acknowledgement: The authors express sincere thanks to the field staff for field data collection during the survey.

Funding: Authors are thankful to the Ministry of Earth Sciences, Government of India for financial support.

Competing Interests: The authors declare that they have no conflict of interests.

Transparency: The authors confirm that the manuscript is an honest, accurate, and transparent account of the study was reported; that no vital features of the study have been omitted; and that any discrepancies from the features of the study have been omit
study as planned have been explained.

Ethical: This study follows all ethical practices during writing.

\section{Contents}

1. Introduction

2. Materials and Methods....

3. Results and Discussion 


\section{Introduction}

Sea urchins belonging to the phylum Echinodermata and class Echinoidea are uniformly distributed in all tropical and subtropical environments. These are benthic organism occur at all the ocean depths. These marine animals acts as biological indicators to assess the environmental health by their sensitivity to the environmental changes or stresses in their habitat [1]. S. variolaris commonly known as black sea urchin belonging to the family Stomopneuidae, are dark blackish with blue sheen on spines, omnivorous and shallow water inhabitants which reside upto a depth of $18 \mathrm{~m}$ [2, 3]. They usually found underneath of rocks or crevices that provide protection against predators, and they are more abundant in zones where waves are less strong [4]. This edible black sea urchin commonly found in Gulf of Mannar which are being consumed as delicious food items from the ancient time by the fishermen communities of Mandapam and Pamban village under Ramnathapuram district of Tamil Nadu [5]. Among the echinoderms, sea cucumber and sea urchins are commercially exploited by Southeast Asian countries, Western Europe, Mediterranean countries, Chile and Pacific North America. The gonads or roe of black sea urchin $S$. variolaris is nutritionally rich in protein (18\%), essential fatty acids, carbohydrates, carotenoids, vitamins and some important trace elements like $\mathrm{Fe}, \mathrm{Zn}, \mathrm{Cu}, \mathrm{Ni}, \mathrm{Cr}$ [6, 7] . In Gulf of Mannar, a total of 264 echinoderms were reported among which 24 species of sea urchin so far recorded from here Saravanan, et al. [8]. Distributional records of echinoids in Gulf of Mannar was mainly carried out from the fish landing centre. Despite of several studies concentrated on commercial important of sea urchin, very few research studies were carried out on sea urchin ecology and aggregation patterns in coral reef environment [9-11]. Therefore, the present study aimed to report photographic evidence of mass aggregation of $S$. variolaris in Shingle Island of Gulf of Mannar and provide information on the favorable habitat of sea urchin S.variolaris aggregation.

\section{Materials and Methods}

Field observations on $S$. variolaris were made by skin diving in South-western part of the Shingle Island during an extensive coral reef monitoring survey carried out in the month of January-February, 2019. Locations of the observation sites $\left(\mathrm{No9}^{\circ} 14.402^{\prime}\right.$, E79 ${ }^{\circ} 14.212^{\prime}$; Site2: No9 ${ }^{\circ} 14.443^{\prime}$, E79 ${ }^{\circ} 14.052^{\prime}$; Site3: No9 ${ }^{\circ} 14.415^{\prime}$, E79 $^{\circ} 14.096^{\prime}$ ) were marked with GPS and underwater photographs of the specimens were obtained with Nikon coolpix underwater camera Figure 1. The habitat of the sites consisted of sand, dead corals and rubbles with abundant macrophyte communities.

\section{Results and Discussion}

$S$. variolaris Figure 2 a was intensively aggregated at the south western part of Shingle Island at a depth range between $0.5 \mathrm{~m}-1.5 \mathrm{~m}$. Habitat of the locations consists of exposed rocky intertidal area and zone of coral reefs with abundant algal cover. Sea waves were not so strong that it swifts rubbles and sand from the substratum. Substratum is mainly composed of sand and rubbles with excessive algal growth. Halimeda sp., and Sargassum sp. was abundantly distributed in the observation sites Figure 2e \& 2f. Average density of the occurrence of $S$. variolaris was 6-9 individuals/ $\mathrm{m}^{2}$. Most individual has a test diameter of $7-11 \mathrm{~cm}$. During the survey, two or more specimens were closely staying on each other Figure $2 \mathrm{~b}$. Single individual were hiding themselves within the crevices or underneath the rocks Figure 2c \& 2d. Many individuals were also lying exposed on the algal bed Figure 2f. No juveniles were sighted on the study sites. Average numbers of 5-10 individuals were recorded in each aggregated colony Figure 2f. They waved their spines slowly, touching and crossing the spines of neighboring sea urchin. To avoid the predator and unwanted objects, all individuals trying to hold the substratum hard and move spines more frequently.

Many animals commonly aggregate to protect themselves from predators, to facilitate prey capture and to reproduce $[12,13]$. But Sea urchin aggregates in response to destructive grazing on algae bed or involve in social interactions [14]. Similarly, during our survey, social interactions and evidence of abundant algal growth were observed in the study area which might be indicated that mass aggregation of $S$. variolaris occurred due to the availability of huge amount of food. Sea urchin species Diadema setosum performed the aggregation behavior for their protection rather than reproduction success [15]. As per the study, it has been concluded that when urchins are too abundant to find shelter among rocks, individuals form aggregations for protection against predators [15]. Here in the present study, individual $S$. variolaris sighted underneath of crevices or within the holes of dead rocks. Aggregated sea urchins are mainly found on the edges of dead rocks or rubbles or on algal bed. Echinoids act as destructive grazers and combat with the invasive algae which is one of the major threat to the coral reefs of Gulf of Mannar [16]. Several studies also evaluated the role of echinoids as a keystone herbivores which could serve as an important tool for local reef conservation and management, especially the reef where overfishing is a major threat $[17,18]$. Similarly, coral reefs in Gulf of Mannar faced severe disturbances from natural and anthropogenic factors including destructive fishing, shoreline operation, and bio invasive species [19]. Algal species such as Sargassum sp, Halimeda sp, Caulerpa sp, Turbinaria sp are the major threats to the degraded reef area in Gulf of Mannar. Hence, such mass aggregation of sea urchin species Stomopneustes variolaris can fight against these invasive algal species and reduce the chances of coral mortality in the reef. However, there is no sign of extrinsic environmental limitations which might affect the distribution of $S$. variolaris in the study area. In Gulf of Mannar, four species of echinoids are used in Souvenir industry [20]. People of Managudi village near Uchipuli of Ramnathapuram district eat the gonads of $S$. variolaris by frying or grilling the gonad Saravanan, et al. [5]. Saravanan, et al. [5] inferred that this villagers consider the gonad of $S$. variolaris as delicacy and their way of cooking is unique. Though, no echinoid species have the commercial value in India but the eating of $S$. variolaris by the local coastal communities brings the sustainable way of improving the food security in Gulf of Mannar villages. However, this observation on mass aggregation of $S$. variolaris in Gulf of Mannar provides both the ecological and commercial significance to the coastal population as well as to coral reefs of Gulf of Mannar. More extensive underwater surveys are required to investigate and evaluate important marine faunal resources that can help in coral reef conservation and sustainable livelihood to coastal population. 


\section{References}

[1] K. Parish, J. Brown, R. Cook, and M. Kapp, "Heavy metals effect on the fertilization and development of sea urchin embryos," 2012.

[2] A. Kroh, "Stomopneustes variolaris (Lamarck, 1816)." http://www.marinespecies.org/echinoidea/aphia.php?p=taxdetails\&id=212440. [Accessed June 12, 2014 ], 2014.

[3] A. B. Smith and A. Kroh, "The Echinoid Directory [Data set]." Available: http://www.nhm.ac.uk/researchcuration/projects/echinoid-directory. [Accessed June 12, 2014], 2014.

[4] J. J. Alvarado, "Seasonal occurrence and aggregation behavior of the sea urchin astropyga pulvinata (Echinodermata: Echinoidea) in Bahía Culebra, Costa Rica1," Pacific Science, vol. 62, pp. 579-593, 2008. Available at: https://doi.org/10.2984/15346188(2008)62[579:soaabo]2.0.co;2.

[5] R. Saravanan, K. K. Joshi, S. I. Syed, N. A. K. Abdul, and S. Chandrasekar, "Traditional knowledge on the edibility of sea urchin roe among the Ffisher folk community of the Gulf of Mannar region with a note on their Cuisine, Posters: Theme: Food, Nutrition, Security," presented at the 1st International Agrobiodiversity Congress, 2008.

[6] Y. Yokota, V. Matranga, and Z. Smolenicka, The sea urchin: From basic biology to aquaculture. Rotterdam: AA Balkema, 2002.

[7] B. K. K. K. Jinadasa, H. K. S. De Zoysa, G. D. T. M. Jayasinghe, and E. M. R. K. B. Edirisinghe, "Determination of the biometrical parameters, biochemical composition and essential trace metals of edible sea urchin (Stomopneustes variolaris) in Sri Lanka," Cogent Food E̊ Agriculture, vol. 2, p. 1143343, 2016. Available at: https://doi.org/10.1080/2331 1932.2016.1 143343.

[8] R. Saravanan, S. I. Sadiq, and P. Jawhar, "Sea Urchin diversity and its resources from Gulf of Mannar, perspectives on biodiv ersity of India: Theme 2 - Marine biodiversity," Indian Biodiversity Congress, vol. 3, pp. 180-182, 2018.

[9] N. Cabanillas-Terán, P. Loor-Andrade, R. Rodríguez-Barreras, and J. Cortés, "Trophic ecology of sea urchins in coral-rocky reef systems, Ecuador," PeerJ, vol. 4, p. e1578, 2016. Available at: https://doi.org/10.7717/peerj.1578.

[10] R. Saravanan, P. Jawahar, T. Francis, B. Ahilan, R. Santhakumar, and G. Gopakumar, "Echinoid landing in Mandapam, South East coast of India with a note on gonadal maturity of two species of sea urchin," Indian Journal of Fisheries, vol. 64, pp. 190-193, 2017. Available at: https://doi.org/10.21077/ijf.2017.64.special-issue.76265-28.

[11] L. A. Neil, "Ecological aspects of the common sea urchin, Evechinus chloroticus, in Northern New Zealand: A review," New Zealand Journal of Marine and Freshwater Research, vol. 22, pp. 415-426, 1988 . Available at: https://doi.org/10.1080/00288330.1988.9516313.

[12] K. H. Jensen and P. Larsson, "Predator evasion in Daphnia: The adaptive value of aggregation associated with attack abatement," Oecologia, vol. 132, pp. 461-467, 2002. Available at: https://doi.org/10.1007/s00442-002-0979-4

[13] P. E. Stander, "Foraging dynamics of lions in a semiarid environment," Canadian Journal of Zoology, vol. 70, pp. 8-21, 1992. Available at: https://doi.org/10.1139/z92-002.

[14] E. S. Reese, The complex behavior of echinoderms. In R. A. Boolootian, Eds. New York: Physiology of Echinodermata. Inter Science, 1966.

[15] J. Pearse and S. W. Arch, "The aggregation behavior of Diadema (Echinodermata, Echinoidea)," Micronesia, vol. 5, pp. 165-171, 1969.

[16] J. K. P. Edward, G. Mathews, K. D. Raj, T. Thinesh, J. Patterson, J. Tamelander, and D. Wilhelmsson, "Coral reefs of Gulf of Mannar, India - signs of resilience," in Proceedings of the 12th International Coral Reef Symposium, Cairns, Australia, 2012.

[17] H. B. S., B. R. Silliman, J. D. Olden, J. P. Bruno, and M. D. Bertness, "Incorporating positive interactions in aquatic restoration and conservation," Frontiers in Ecology and Environment, vol. 5, pp. 153-160, 2007.

[18] A. Rogers and K. Lorenzen, "Recovery of Diadema antillarum and the potential for active rebuilding measures: Modeling population dynamics," in Proceedings 11 th International Coral Reef Symposium, Ft. Lauderdale, 2009, pp. 956-960.

[19] J. K. Edward, G. Mathwes, D. Raj, R. L. Laju, M. S. Bharath, A. Arasamuthu, P. Dinesh Kumar, D. S. Bilgi, and H. Malleshappa, "Coral Mortality in Gulf of Mannar, Southeastern India, due to bleaching caused by elevated sea temperature in 2016," Current Science, vol. 114, pp. 1967-1972, 2018.

[20] C. Chellaram, V. D. Samuel, and J. K. P. Edward, "Status of echinoderm fishery in the Gulf of Mannar, Southeast coast of India," SDMRI Res. Pub, vol. 3, pp. 173-176, 2003.
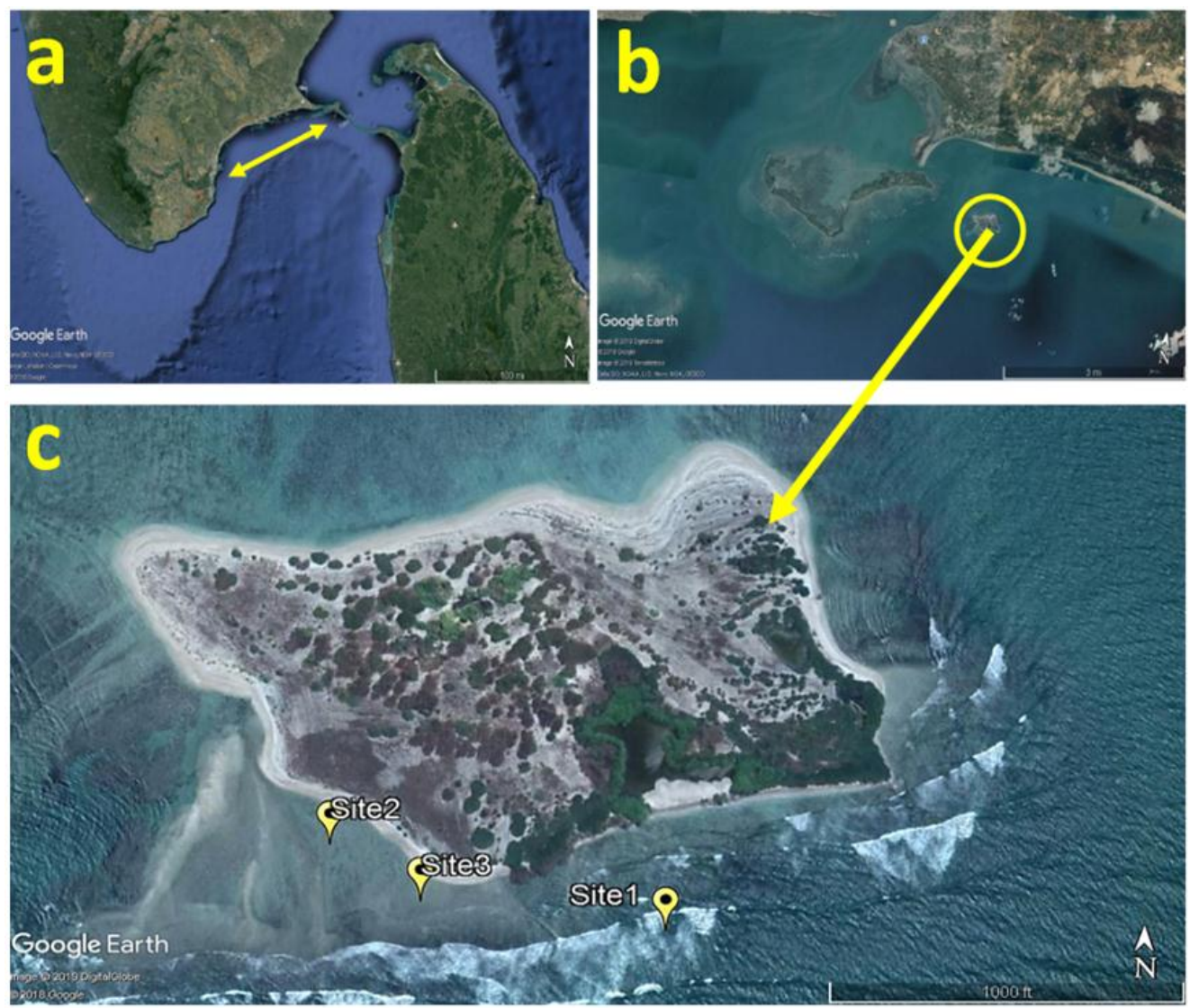

Figure-1. a. Arrow showing the Gulf of Mannar region; b. Shingle Island along with neighboring island of Gulf of Mannar; c. Observation sites in Shingle Island.

Source: Google Earth. 


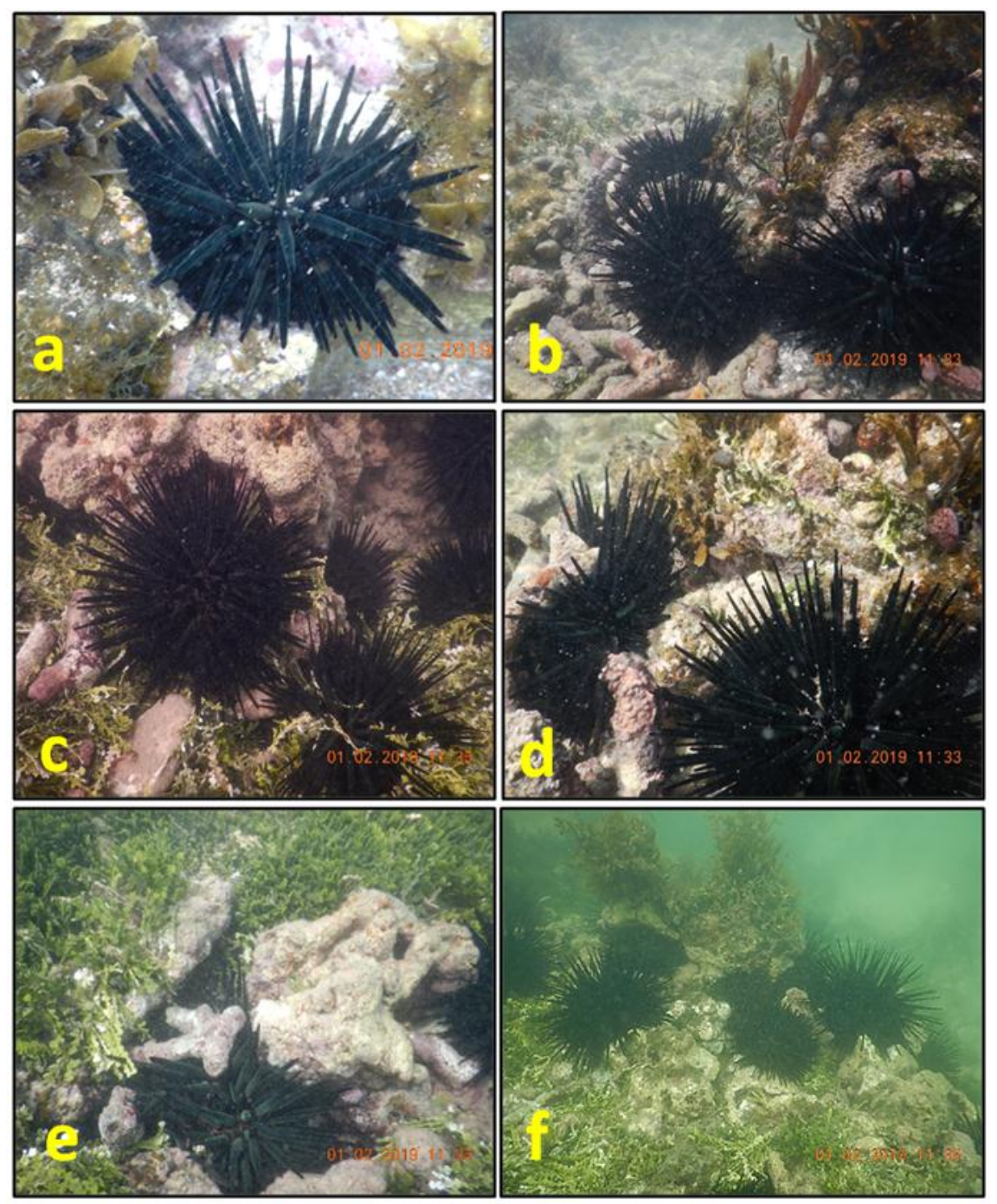

Figure-2 a. Stomopneustes variolaris - single specimen. b. Aggregation of 5-6 individuals together on rubbles. c. \& d. Individuals hide inside the crevices or dead rocks; e. S. variolaris with invasive algae Halimeda sp.; f. aggregated $S$. variolaris lying on the dead rubbles covered with algae.

Source: Present work, NCCR, MoES. 